\title{
Analysis of the Efficiency of Various Waste Electrical and Electronic Equipment's Collection Routes: A Case Study Focusing on Collection Route for Waste Mobile Phones in the Tohoku Area of Japan
}

\author{
Xiaoyue Liu *, Jeongsoo Yu (D) and Kazuaki Okubo \\ Graduate School of International Cultural Studies, Tohoku University, Sendai 980-8576, Japan; \\ jeongsoo.yu.d7@tohoku.ac.jp (J.Y.); kazuaki.okubo.d5@tohoku.ac.jp (K.O.) \\ * Correspondence: liu.xiaoyue.p4@dc.tohoku.ac.jp
}

check for updates

Citation: Liu, X.; Yu, J.; Okubo, K. Analysis of the Efficiency of Various Waste Electrical and Electronic Equipment's Collection Routes: A Case Study Focusing on Collection Route for Waste Mobile Phones in the Tohoku Area of Japan. Recycling 2021, 6, 13. https://doi.org/10.3390/ recycling6010013

Received: 31 December 2020

Accepted: 3 February 2021

Published: 18 February 2021

Publisher's Note: MDPI stays neutral with regard to jurisdictional claims in published maps and institutional affiliations.

Copyright: (c) 2021 by the authors. Licensee MDPI, Basel, Switzerland. This article is an open access article distributed under the terms and conditions of the Creative Commons Attribution (CC BY) license (https:// creativecommons.org/licenses/by/ $4.0 /)$.

\begin{abstract}
Each year, more than 5 million Waste Mobile Phones (WMP) is generated in Japan. Since WMPs contain many rare metals and precious metals, it is essential to collect and recycle high-value metal resources from them effectively. Although multiple stakeholders have already developed WMP collection routes, these WMP collection routes' current status is unclear. Furthermore, some WMP collection routes can only collect a small number of WMP, and so, their resource efficiency is low. This research aims to clarify each WMP collection route's characteristics and evaluate their resource efficiency by conducting interview research on related stakeholders and the WMP dismantle experiment. The result shows that local government, authorized recyclers, and telecom carriers are the major stakeholders in collecting WMPs in Japan. To improve the WMP collection rate in cities with high population densities, using the local government's collection route and installing an authorized recycler's collection station is considered to be more effective. In cities with low population densities, the collection stations built by authorized recyclers are sufficient. The collection stations can also improve recycling behavior by offering points. Furthermore, the telecom carriers are encouraged to participate in the WMP collection business, but they should figure out a way to monitor the flow route of secondhand phones they exported and prompt the proper recycling of exported phones.
\end{abstract}

Keywords: electrical and electronic equipment; waste mobile phone; collection route; resource efficiency; japan

\section{Introduction}

Since 1995, along with economic development, mobile phones have become popular in Japan. By the end of 2011, the total number of mobile phone contracts in Japan exceeded the total Japanese population [1]. Furthermore, in 2016, the penetration rate of mobile phones in Japan reached 70\% [2]. Therefore, it is easy to predict that the number of mobile phones in Japan will keep increasing in the future. However, during the manufacturing process of mobile phones, a massive amount of natural metal resources are required, and unfortunately large amounts of rare metals and precious metals are unevenly distributed. For instance, most of the tungsten $(\mathrm{W})$, zinc $(\mathrm{Zn})$, manganese $(\mathrm{Mn})$, lead $(\mathrm{Pb})$, palladium $(\mathrm{Pd})$, and platinum $(\mathrm{Pt})$ that are used in mobile phones are extracted from the natural reserves of China, Mexico, Russia, and South Africa [3]. As Japan lacks these resources, it is necessary for the Japanese government to maintain a stable supplement of these natural metal resources.

Since the 1980s, the number of waste home appliances generated in Japan began to quickly increase. A total of $650 \mathrm{kt}$ of small household appliances is generated as waste in Japan each year. According to the estimation proposed by the Ministry of the Environment 
of Japan, the metal inside these waste small household appliances is equivalent to 84.4 billion yen [4]. From this point of view, it is fair to say that Japan is rich in metal resources. This kind of metal resources is called an "Urban mine".

According to the Sustainability Design Institute, the gold $(\mathrm{Au})$ reserved in Japanese urban mine is around $6.9 \mathrm{kt}$ (equivalent to $11 \%$ of the world's existing Au reserves) and silver (Ag) is about $60 \mathrm{kt}$ (equivalent to 10\% of the world's existing Ag reserves). Other metals (such as tin (Sn), and antimony (Sb)) in Japanese urban mines accounts for more than $10 \%$ of the world's reserves [5,6]. Therefore, it is important for the Japanese government and related stakeholders to recycle these resources from urban mines (especially from Waste Mobile Phones (WMPs), since their operable time is shorter (about 3 to 4 years) and contains comparatively more rare and precious metal resources) and reuse the resources in manufacturing new mobile phones [7,8]. In addition, mobile phones contain many hazardous substances (such as heavy metals, flame retardants, etc.) as well. Therefore, if mobile phones cannot be recycled appropriately, they may significantly influence human health and the environment [9]. Thus, researchers in Japan and worldwide have focused on the effective utilization of mobile phones in the urban mine [10].

However, although some metal smelting and refining companies (such as DOWA) have installed advanced recycling technology and facilities to recover high-purity metals from waste products since the 2000s, only a small number of WMP can be collected in Japan [11]. As a matter of fact, although it is estimated that more than 5 million WMPs generates as waste in Japan each year [12], approximately $40 \%$ of the WMPs are stored at home instead of being recycled [13]. To guarantee the collection amount of WMPs, multiple WMP collection routes have been established in Japan. For instance, the government of Japan has installed the "Act on Promotion of Recycling of Small Waste Electrical and Electronic Equipment" (hereinafter called "Small Home Appliance Recycling Law") from 2013 [14]. Under this law, local municipalities cooperate with authorized recyclers in collecting WMPs. However, although the "Small Home Appliance Recycling Law" has defined the stakeholders (the national government, local governments, consumers, and recycling companies) in the WMP collection industry, the law is not mandatory, each stakeholder can decide whether to participate in the system or not based on their interest and thus the effect is not significant [15]. On the other hand, telecom carriers cooperated with mobile phone dealers and launched the "Mobile Recycle Network (MRN)" to collect the main body, battery, and charger of mobile phones from users in 2001. Yet, the number of collected WMPs through MRN has been decreasing over these years [16].

In other words, although an effective WMP collection route is important and multiple WMP collection routes have been established in Japan [17], the current WMP collection rate in Japan is ineffective [13].

Based on such a background, the research set two main research goals. The first one is to investigate and clarify the current status, characteristics, and issues of each WMP collection route in Japan. The second one is to evaluate and compare the resource efficiency of each WMP collection route in Japan.

Based on the research result above, this paper aims to propose solid suggestions to improve the WMP collection rate in Japan in the future. The research result of this paper can be used in countries that also face WMP collection problems.

\section{Material and Methods}

To fulfill these research goals, we performed two research methods. The detailed research method and the flow of this research is shown in Figure 1. 

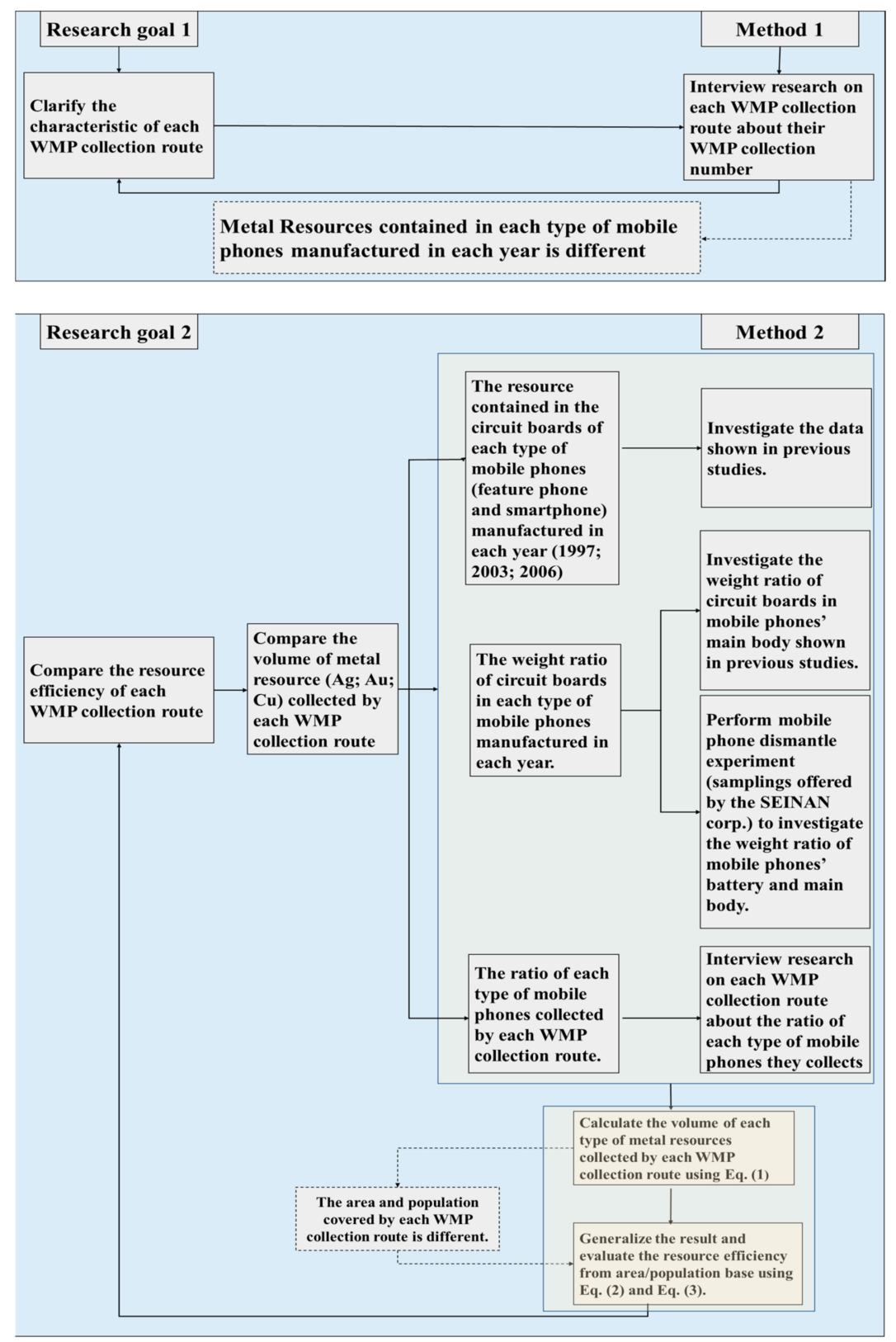

Figure 1. Detailed research method and the flow of this research. WMP: Waste Mobile Phones.

\subsection{Interview Research on Stakeholders}

In order to clarify the characteristics of each WMP collection route, it is necessary to verify the stakeholders in the WMP collection system in Japan and conduct interviews. The interview research also investigates the number of WMP collected by each WMP collection route. Expected stakeholders in this research are the local governments, the authorized WMP recyclers, and the telecom carriers in the Tohoku area. Through faceto-face interviews and email interviews, specific information about collection routes and stakeholders in the Tohoku area were collected. The interview questions are shown in Appendix A.

\subsection{Resource Efficiency Evaluation Method}

Although the number of collected WMP can represent the resource efficiency of each WMP collection route to some degree, since the resource volume contained in each type of mobile phone manufactured in each year is different, to fairly compare the resource efficiency of each WMP collection route, the volume of metal resource collected by each 
WMP collection route should be compared. More specifically, the research focused on three types of metals used in WMPs ( $\mathrm{Au}, \mathrm{Ag}$, and copper $(\mathrm{Cu}))$, and presumed that these metals are mainly recovered from WMPs' circuit boards.

\subsubsection{Metal Resources Contented in Mobile Phones' Circuit Boards}

Data that relates to the metal resources used in mobile phone circuit boards were collected from previous studies. More specifically, the resource content of circuit boards in feature phones were collected from the "Test Result of Metal Content in Small Home Appliances" (feature phones made in 1997, 2003, and 2006) [18]. However, since only the feature phones made in 1997, 2003, and 2006 have been investigated, the data in 1997 represent the resource volume of feature phones manufactured before 2003, the data in 2003 represent the resource volume of feature phones made between 2003 and 2005, while the data in 2006 represent the resource volume of feature phones made in and after 2006 in this research.

According to Table 1, the Au and Ag in feature phone circuit boards have been decreasing in these years, while the content of $\mathrm{Cu}$ keeps increasing along with the development of phone manufacturing technology. On the other hand, the average content of each type of metal in smartphone circuit boards is $0.21 \%(\mathrm{Au}), 0.54 \%(\mathrm{Ag})$, and $38.29 \%(\mathrm{Cu})$, respectively [19].

Table 1. The metal content of circuit boards.

\begin{tabular}{ccccc}
\hline Materials & \multicolumn{3}{c}{ Feature Phone } & Smartphone \\
\hline & $\mathbf{1 9 9 7}$ & $\mathbf{2 0 0 3}$ & $\mathbf{2 0 0 6}$ & \\
\hline $\mathrm{Au}$ & $0.18 \%$ & $0.14 \%$ & $0.12 \%$ & $0.21 \%$ \\
$\mathrm{Ag}$ & $0.13 \%$ & $0.063 \%$ & $0.065 \%$ & $0.54 \%$ \\
$\mathrm{Cu}$ & $28 \%$ & $32 \%$ & $38 \%$ & $38.29 \%$ \\
\hline
\end{tabular}

\subsubsection{Weight Ratio of Circuit Boards in Mobile Phones}

Two sub-research methods were performed to investigate the weight ratio of circuit boards in mobile phones.

The first one is to know the weight ratio of circuit boards in the main body of each type of mobile phone. The data were collected from Saito and Yu's WMP dismantling experiment [20]. According to Saito and Yu, the proportion of circuit boards in the main body of mobile phones changes from $28 \%$ (in 1997) to $22 \%$ (in 2003 and 2006). Furthermore, not all the metal resources in circuit boards can be recycled during the recycling process. According to Morishita [21], 60\% of metal can be recovered during the small home appliances' recycling process.

Then, the weight ratio of mobile phones' main body and battery need to be investigated. To do so, the authors collected 311 qualified WMP samples out of 340 total WMP samples from SEINAN corporation in 2018 (during the sample selection process, 29 samples were excluded due to the lack of phone batteries, necessary data, or if the sample was a plastic model for exhibition) and performed a dismantling experiment. Among all the 311 samples, 121 samples were feature phones, while 190 samples were smartphones. Furthermore, 25 samples were iPhones, which accounted for $8 \%$ of the total samples and $13 \%$ of smartphones.

As shown in Figure 2, each sample was dismantled into a phone battery and the main body during the dismantle experiment. The maker, manufacture date and location, phone type (feature phone or smartphone), phone weight, battery type (Lithium battery or NiMH battery), and weight were particularly investigated since these factors would dramatically affect a mobile phone's resource content. 

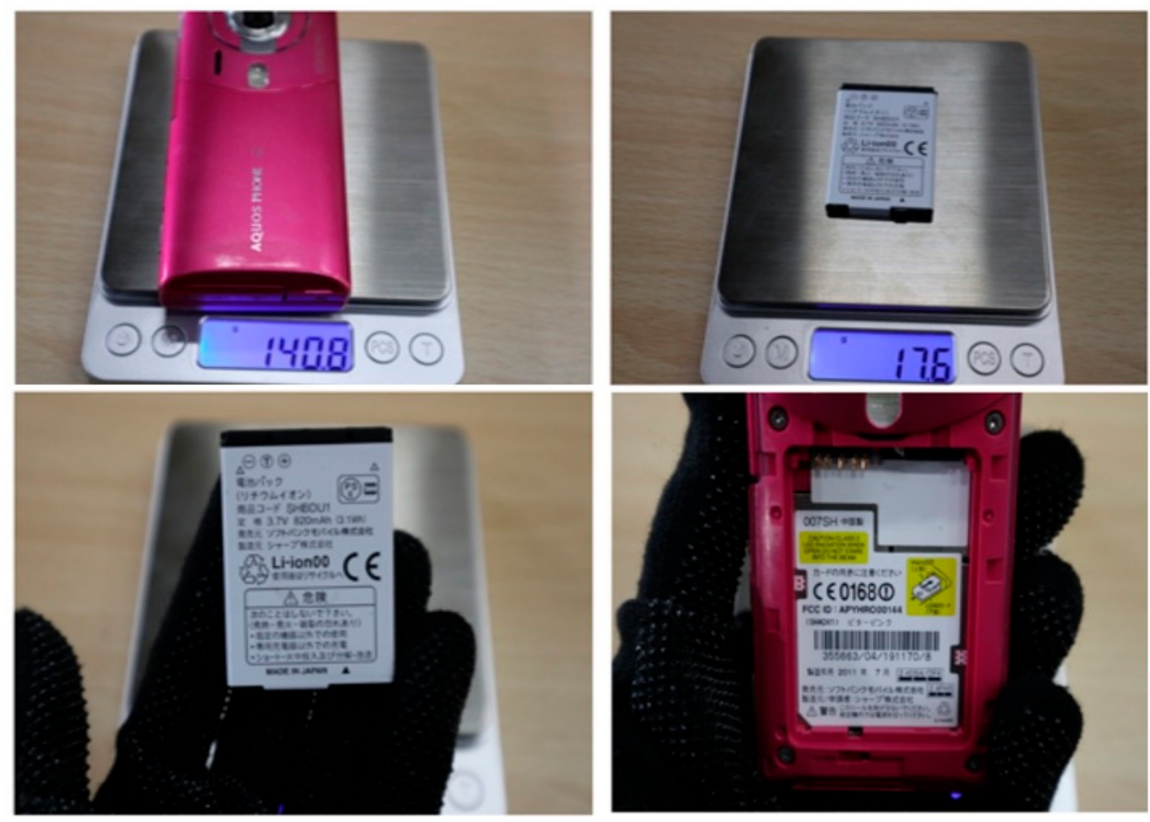

Figure 2. Sample selection and data collection experiment.

\subsubsection{Ratio of Each Type of Mobile Phones Collected by Each WMP Collection Route}

Since mobile phones have become widespread since the 1990s, not only has the design, function, and manufacturing technology, significantly changed throughout the years, but so has the resource content. Therefore, to clarify the characteristic (ratio of feature phone and smartphone) of WMPs, an interview research was performed on stakeholders in each WMP collection route.

\subsubsection{Calculation Method for the Resource Efficiency of Each WMP Collection Route}

Based on the above information (from Sections 2.2.1-2.2.3), the method to calculate the recoverable weight of a specific type of metal from a particular type of WMP (the resource efficiency of a specific WMP collection route) (Y) can be found in Equation (1):

$$
\mathrm{Y}=\mathrm{N} \times \mathrm{Wb} \times \mathrm{Rc} \times \mathrm{Rm} \times 0.6
$$

where N means "the number of a certain type of collected WMPs", Wb shows "the average weight of WMPs' body", Rc represents "the proportion of circuit board in WMPs' main body", Rm demonstrates "the resource volume of a circuit board", and 0.6 means the recovery rate of a type of metal during the recycling process [21].

However, since each WMP collection route covers different areas and different amounts of population, to fairly evaluate the resource efficiency of each WMP collection route, as well as to generalize the research result (so that the result can be suitable for all parts of Japan instead of the Tohoku area only), the resource efficiency of each WMP collection route was evaluated from two perspectives (area base and population base). The data relating to the area and population that each collection route can cover were referenced from the Miyagi Prefectural Government and Aomori Prefectural Government, respectively [22-24]. The calculation method is shown in Equations (2) and (3):

$$
\operatorname{Ep}(\mathrm{g} / 10,000 \text { capita })=Y \mathrm{t} / \mathrm{P}
$$

where, $\mathrm{Yt}$ is the total recoverable weight of a specific type of metal from collected WMPs, and $\mathrm{P}$ means "the resident population that can be covered by a certain type of WMP collection route".

$$
\mathrm{Ea}\left(\mathrm{g} / \mathrm{km}^{2}\right)=\mathrm{Yt} / \mathrm{A}
$$


where, Yt refers to the total recoverable weight of a specific type of metal from collected WMPs, and A shows "the size of an area that can be covered by a certain type of WMP collection route".

\section{Results and Discussion}

In this section, based on the interview research result, original experiment, and calculation, we clarified the characteristic of each WMP collection route and demonstrated each collection route's resource efficiency.

\subsection{Stakeholders and Characteristics of Each WMP Collection Route \\ 3.1.1. Stakeholders of Each WMP Collection Route}

As mentioned before, the Japanese government have installed the "Small Home Appliance Recycling Law" in 2013. According to our investigation, $79.3 \%$ of municipality governments in the Tohoku area have installed such a law and are cooperating with authorized WMP recyclers to collect WMPs by 2017 [25]. Moreover, authorized recyclers in the Tohoku area have their independent original WMP collection route as well.

Furthermore, besides the local governments and authorized recyclers, the telecom carriers and electronic stores can also collect WMPs from phone owners (normally, consumers in Japan will sign a 2-year contract with telecom carriers and get a brand new phone. The old phones will be discarded at the same time).

Therefore, the stakeholders included in this research refers to the local government (namely the Environment Bureau of Miyagi Prefecture, Environment Bureau of Sendai City), two authorized recyclers (namely SEINAN corporation and the NIKKO corporation), two telecom carriers (refers to Docomo and Softbank), and the MRN (Figure 3).

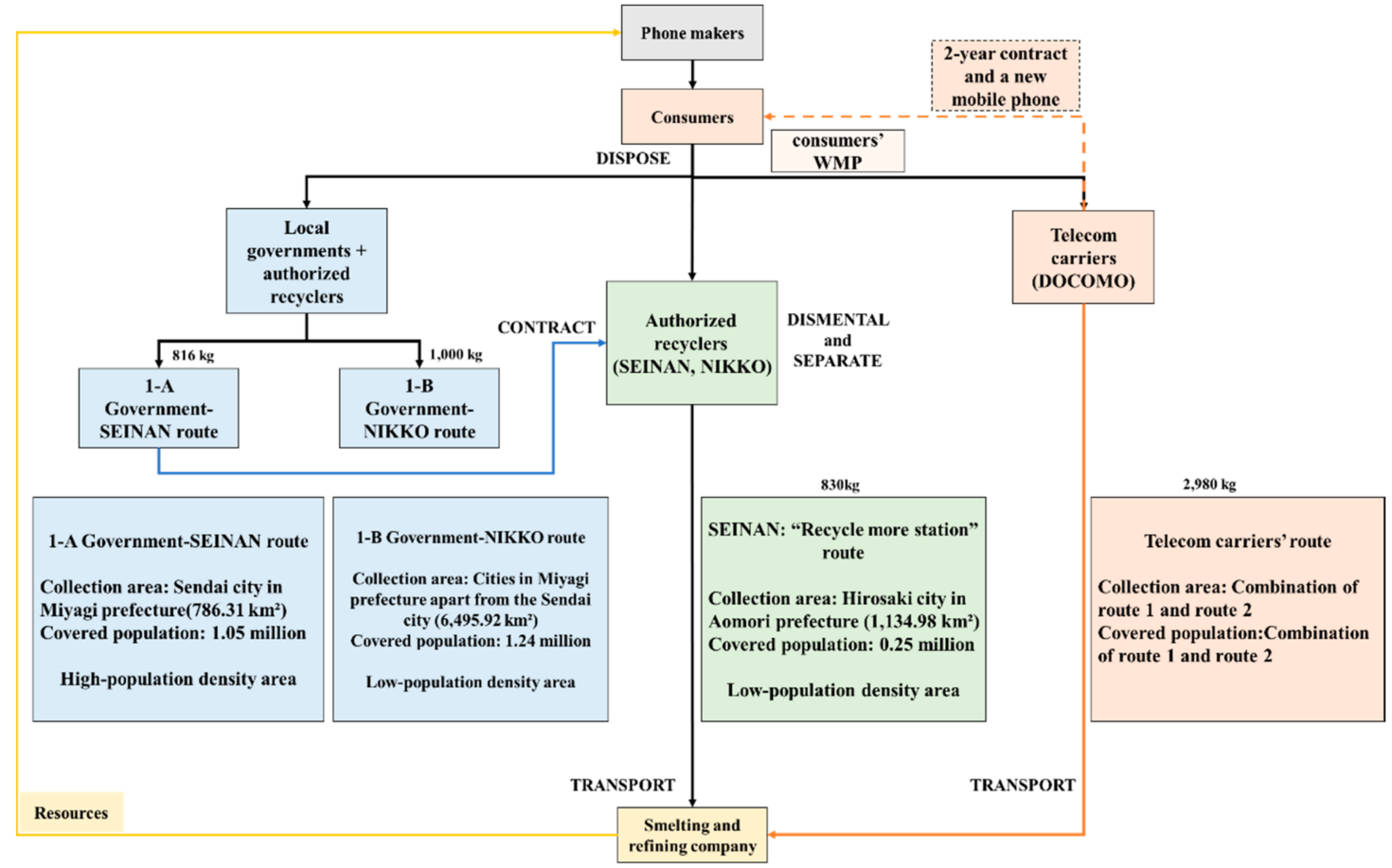

Figure 3. The main stakeholders of WMP collection and the recycling industry in the Tohoku area.

\subsubsection{Characteristics of Each WMP Collection Route}

Route 1: Cooperation between local governments and authorized recycler

The local governments in the Tohoku area are collecting WMPs following the "Small Home Appliance Recycling Law". Local governments are collecting the WMP using multiple methods. For instance, there is the "regular collection route" (one to two times 
per week), by setting collection boxes in public or civic facilities (such as the city hall or supermarkets), or by holding civic events to prompt a WMP collection number.

Then, the collected WMPs will be sold to the authorized recyclers. Since the local governments are cooperating with two different authorized WMP recyclers and the area/population covered by these two authorized recyclers are different, the routes were divided into "1-A route (SEINAN)" and "1-B route (NIKKO)".

According to our interview research, $816 \mathrm{~kg}$ of WMPs were collected by the 1-A route in 2018 (SEINAN). These WMPs are mainly from Sendai city, and 70\% of the collected WMPs were feature phones, while only $30 \%$ were smartphones. On the other hand, NIKKO (1-B route) can collect $1000 \mathrm{~kg}$ of WMPs per year. The WMPs that NIKKO collects were from the cities in Miyagi prefecture, which is apart from Sendai city. Among all the collected WMPs by NIKKO, $80 \%$ were feature phones, and $20 \%$ were smartphones.

However, although local governments can collect WMPs stably, the collection brought a heavy economic burden on local governments because of the high recycling cost (especially human cost) [26] and low selling price of WEEEs (to authorized recyclers). Moreover, the proportion of WMP (which contains more high-priced metal resources) in collected WEEEs has dropped to only $2 \%$ in collecting boxes.

Route 2: Authorized recycler's own collection route

Authorized recyclers are establishing their own original collection stations to collect more resources (such as PET bottles, aluminum cans, and magazines). For instance, the SEINAN corps has built multiple resource collection stations called a "Recycle More" station. When the residents deliver their waste to collection stations, the collection stations will provide a certain number of points or awards to the residents. According to SEINAN, $415 \mathrm{~kg}$ of WMPs were collected by the "Recycle More" collection station from June to December of 2018. Therefore it is reasonable to predict that the "Recycle More" collection station could collect $830 \mathrm{~kg}$ of WMPs per year. The ratio of feature phones in collected WMPs was $70 \%$, while other WMPs were smartphones. After collection, SEINAN will dismantle the WMPs manually and remove batteries. Then, a machine will then crush the body of mobile phones. Crushed materials will automatically be sorted into circuits, iron, and plastic by sensors (Figure 4). These materials will then be sold to smelting and refining companies in Japan.
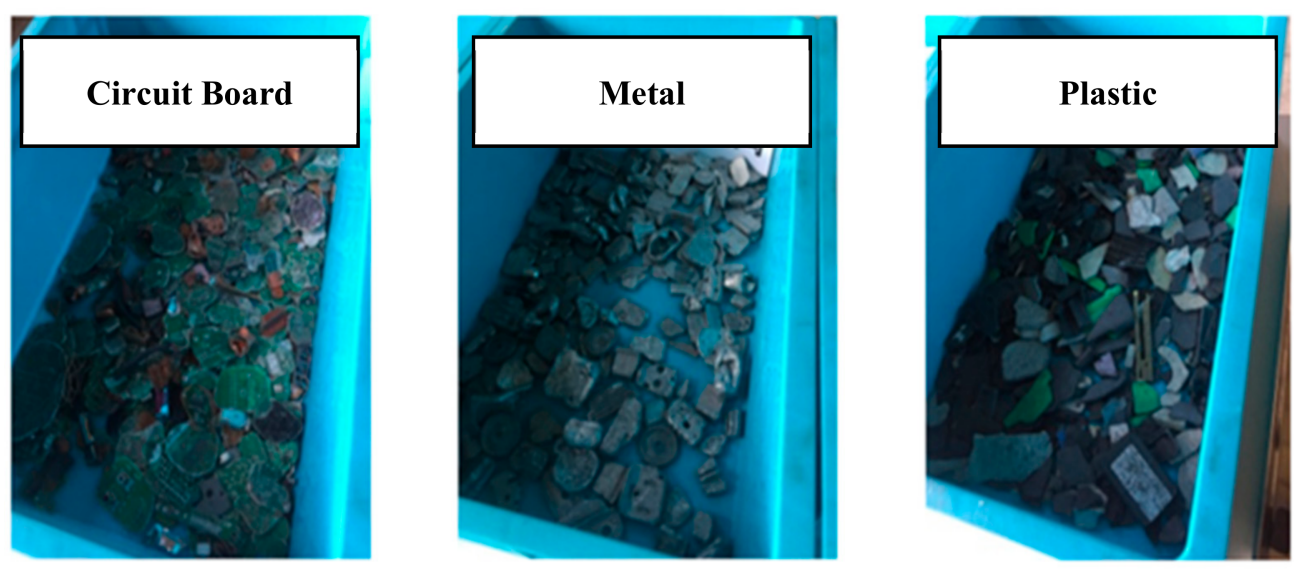

Figure 4. Sorted resources from WMPs.

The advantage of such a method is significant since it is efficient even in areas with a low population density (credits to the high vehicle ownership rates in Japan). These collection stations can also guarantee the stable collection of wastes at a comparatively low cost.

Route 3: Collection route of telecom carriers

Telecom carriers are also collecting WMPs by installing "old-for-new" or "collecting for free" projects. Consequently, telecom carriers can collect a large amount of WMP. 
We performed research interviews with both DOCOMO and Softbank. Currently, as DOCOMO is the largest telecom carrier in Japan [27], we used the data from DOCOMO to represent the status of telecom carrier collection routes. According to our interview research, DOCOMO can collect $2980 \mathrm{~kg}$ of WMPs from the Miyagi prefecture per year. The ratio of feature phones and smartphones collected by DOCOMO is 3:1.

As a matter of fact, the telecom carriers have the most advantages in collecting WMPs, since it is possible for them to collect WMPs when the consumers sign new contracts with them. However, as the demand for secondhand mobile phones has been expanding in recent years (especially for iPhones), part of the WMPs will be exported to developing countries such as South Africa and China (through Hong Kong) after their memories are refreshed. In other words, some WMPs are reused rather than recycled.

Furthermore, since 2017 the telecom carriers and the Japanese government have also started a special WMP collection route called the "Tokyo 2020 Medal Project". The aim of such a collecting route is to secure a certain amount of WMPs while raising public awareness of recycling. The metals recycled from collected small home appliances (especially from WMPs) will be used for producing medals for the Tokyo Olympics.

However, since the project finished in April 2019, the evaluation of such a collection route is out of our research scope.

The characteristic of each collection route is shown in Table 2 and the weight of WMPs collected by each collection route is shown in Figure 5 .

Table 2. Characteristics of three types of collection routes.

\begin{tabular}{cccc}
\hline $\begin{array}{c}\text { Type of Collection } \\
\text { Route }\end{array}$ & Route 1 & Route 2 & Route 3 \\
\hline Collection Method & $\begin{array}{c}\text { Regular collection, } \\
\text { Collecting Box }\end{array}$ & Recycling Station & $\begin{array}{c}\text { "old-for-new", } \\
\text { "collecting for free" }\end{array}$ \\
\hline Stakeholder & $\begin{array}{c}\text { Local governments, } \\
\text { Authorized Recyclers }\end{array}$ & Authorized Recyclers & Telecom carriers \\
\hline Profitability & Low & High & Unclear \\
\hline Merit & Stable Collection & Low Cost & Low Cost \\
\hline Demerit & Low volume of & Unstable Collection & $\begin{array}{c}\text { Expert Oversea Risk } \\
\text { (less metals can be } \\
\text { recycled } \\
\text { domestically) }\end{array}$ \\
\hline
\end{tabular}

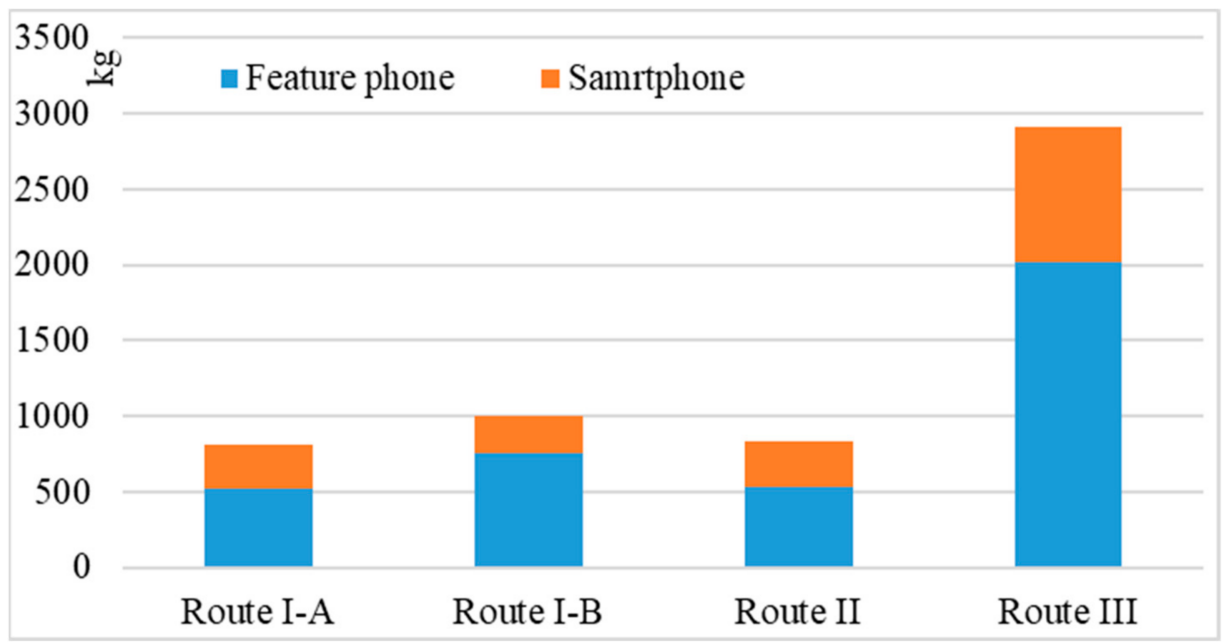

Figure 5. The weight and type of collected WMPs under each collection route. 


\subsection{Characteristics of WMPs}

\subsubsection{Weight Ratio of the Circuit Board in Mobile Phones}

Data relating to the weight ratio of circuit boards in a phone's main body as shown in Table 3, was collected from the WMP (feature phone) dismantling experiment performed by Saito and $\mathrm{Yu}$ [20]. According to Saito and $\mathrm{Yu}$, the proportion of circuit boards in phones decreased from $28 \%$ (in 1997) to $22 \%$ (in 2003 and 2006). The weight ratio of circuit board in a smartphone's main body is set to be $24 \%$ (average weight ratio of circuit boards in feature phones).

Table 3. The weight ratio of circuit boards in the main body of mobile phones.

\begin{tabular}{ccccc}
\hline Type of Phones & $\mathbf{1 9 9 7}$ & $\mathbf{2 0 0 3}$ & Feature Phone \\
\cline { 2 - 5 } & 67.25 & 93 & 102 & 103 \\
\hline $\begin{array}{c}\text { Average weight of } \\
\text { the main body of } \\
\text { phones (g) }\end{array}$ & $28 \%$ & $22 \%$ & $22 \%$ & $24 \%$ \\
\hline $\begin{array}{c}\text { Weight ratio of } \\
\text { the circuit board in } \\
\text { WMPs' body }\end{array}$ & & & \\
\hline
\end{tabular}

\subsubsection{Manufacture Year of WMPs}

Figure 6 shows the manufacturing year of WMPs. It is clear that most waste smartphones were manufactured in 2013. In other words, most of users dispose their smartphones after using them for 4 to 5 years (generally speaking, telecom carriers will only sell the latest model of phones of the year and the model in the previous year). The research result consists of the data published by the Cabinet Office of Japan [28], which claims that the average operable time of a mobile phone is 4.9 years. It is also noticeable that a large part of collected WMPs (especially smartphones) was manufactured 6 to 7 years ago as well. This demonstrates that for some users, even after having a new mobile phone, they will still keep their old phones for a few years.

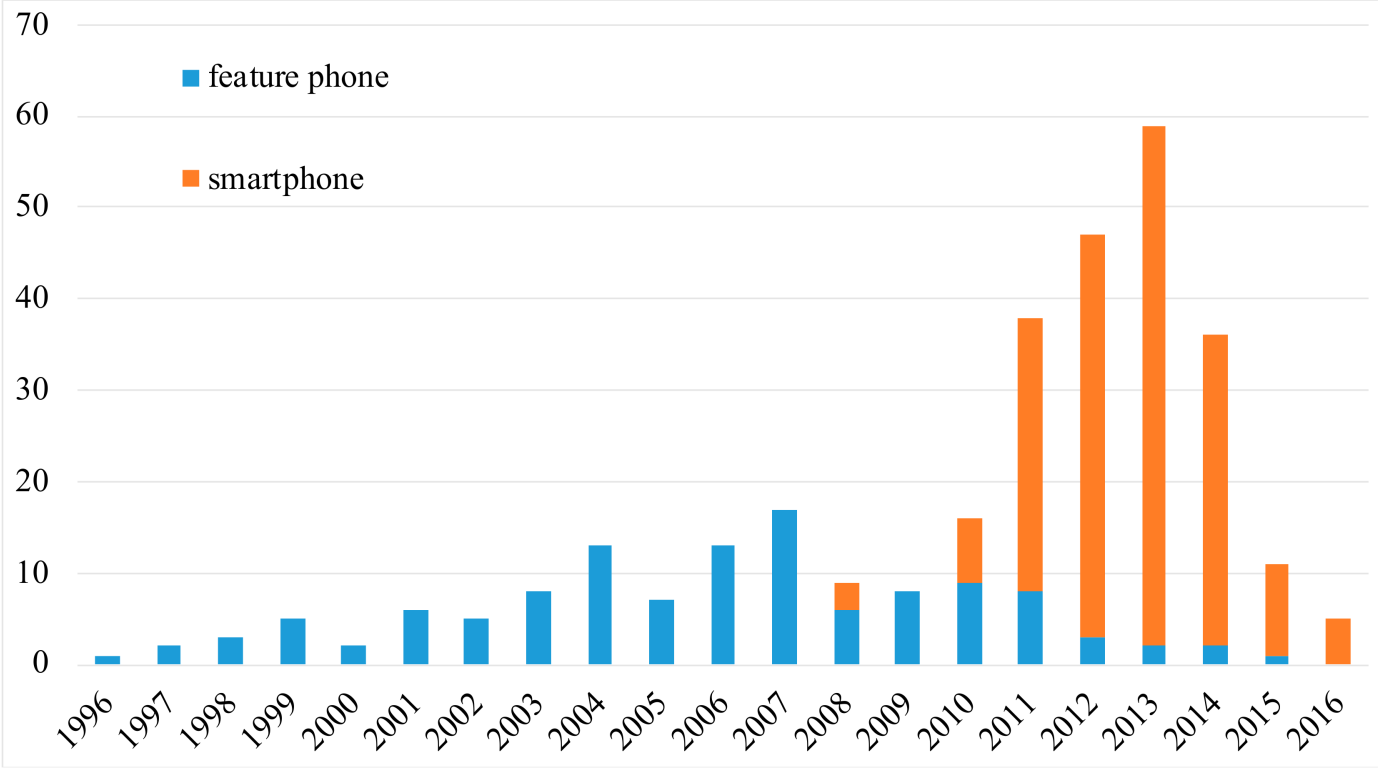

Figure 6. The number of WMPs manufactured each year.

On the other hand, as for feature phones, most of them were manufactured in 2007. In other words, it will take about 10 years for a mobile phone user to discard a feature phone. 
It is possible that, compared to smart phones, the users will keep waste feature phones for a longer time.

\subsubsection{Weight of WMPs' Battery and Main Body}

Figure 7 shows the weight of WMPs manufactured in each year. The average weights of feature phones and smartphones are $108 \mathrm{~g}$ and $142 \mathrm{~g}$, respectively. A smartphone is $34 \mathrm{~g}$ heavier than a feature phone. It is plain to see that the weight of a feature phone (main body weight) is increasing since the late 1990s and reached $110 \mathrm{~g}$ by 2006 (1.5 times to 1.8 times compared to the 1990s). On the other hand, the weight of smartphones (main body weight) has been stable at around $105 \mathrm{~g}$ since 2010, which means that smartphones have changed little in these years. Moreover, the main body weight of a feature phone and smartphone have tended to be the same since the late 2000s.

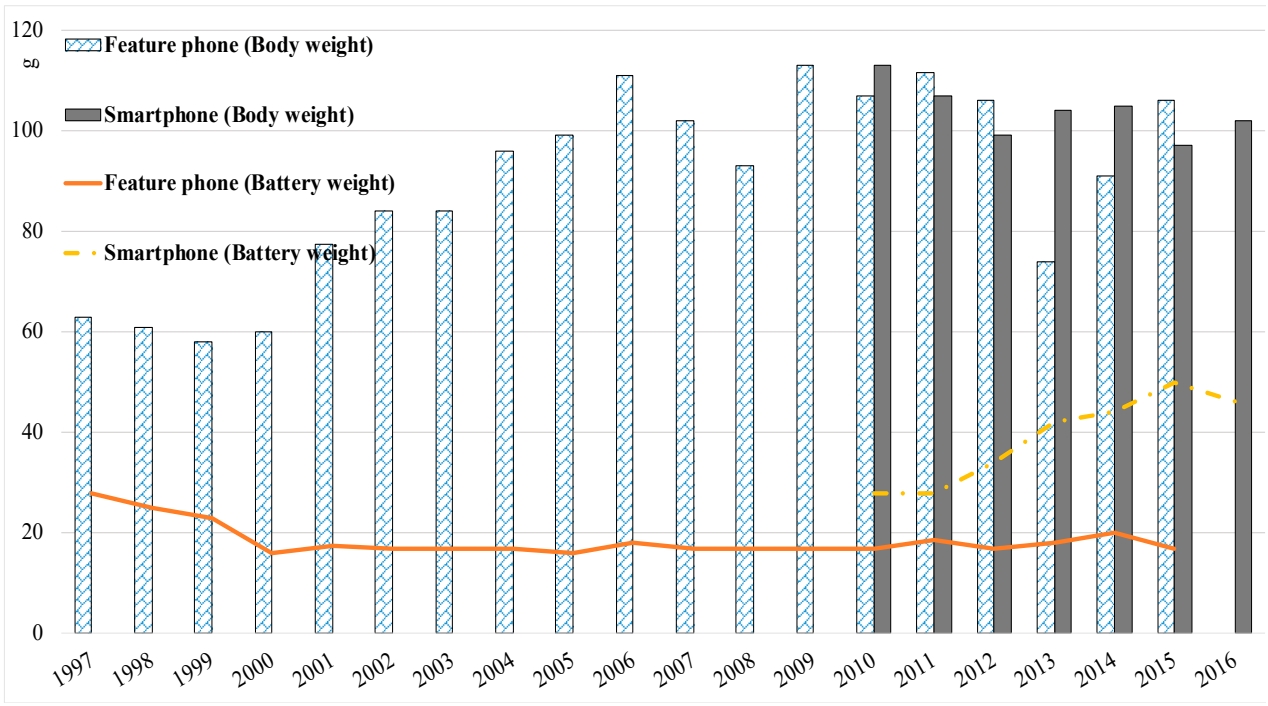

Figure 7. Average body and battery weight for each type of WMPs.

As for the weight for batteries, it is clear that the weight of a feature phone's battery has remained at $17 \mathrm{~g}$ for over 10 years, and so, it is reasonable to presume that their capacity has not greatly changed. In contrast, the smartphone battery weight has been increasing since 2012 and reached around $50 \mathrm{~g}$ in 2015. Therefore, the cobalt (Co) used in smartphone batteries is increasing. That is to say, more resources will be consumed during the manufacturing process of these batteries.

\subsection{Resource Efficiency of Each WMP Collection Route}

\subsubsection{Total Resource Efficiency of Each WMP Collection Route}

Table 4 shows the total collectable resource of $\mathrm{Au}, \mathrm{Ag}$, and $\mathrm{Cu}$ of each WMPs collection route. When looking the weight of total collectable metal resources, route 3 is the most effective collection route. This is because DOCOMO have the widest WMP collection range. One more thing worth noticing is that Route 3 collects the most Ag. The reason for this phenomenon is that, compared to other collection routes, Route 3 can collect more smartphones, which contains more silver than feature phones. On the other hand, since feature phones contains more gold and copper, it is reasonable to predict that Route 1-B can recycle more feature phones. 
Table 4. The weight of total collectable resource under each WMP collection route in 2017.

\begin{tabular}{ccccc}
\hline Type of Collection Route & Route 1-A & Route 1-B & Route 2 & Route 3 \\
\hline $\mathrm{Au}(\mathrm{kg})$ & 0.19 & 0.21 & 0.19 & 0.64 \\
$\mathrm{Ag}(\mathrm{kg})$ & 1.18 & 1.53 & 1.20 & 4.32 \\
$\mathrm{Cu}(\mathrm{kg})$ & 41.12 & 47.51 & 41.80 & 142.42 \\
\hline
\end{tabular}

However, as we mentioned before, since each collection route covers a different area and population, the research will further evaluate the resource efficiency from an area perspective and population perspective.

\subsubsection{Resource Efficiency of Each WMP Collection Route on Area and Population Base}

The resource efficiency of each WMP collection route evaluated from an area and population base is shown in Table 5 .

Table 5. Resource efficiency of each WMP collection route in 2017.

\begin{tabular}{lcccc}
\hline $\begin{array}{c}\text { Type of Collection } \\
\text { Route }\end{array}$ & Route 1-A & Route 1-B & Route 2 & Route 3 \\
\hline $\begin{array}{l}\text { Population base } \\
(\mathrm{g} / 10,000 \text { people })\end{array}$ & & & & \\
$\mathrm{Au}$ & 1.79 & 1.66 & 7.55 & 2.77 \\
$\mathrm{Ag}$ & 11.22 & 12.3 & 47.34 & 18.84 \\
$\mathrm{Cu}$ & 392.34 & 381.91 & 1653.22 & 621.38 \\
\hline $\mathrm{Area}$ base $\left(\mathrm{g} / \mathrm{km}^{2}\right)$ & & & & \\
$\mathrm{Au}$ & 0.24 & 0.03 & 0.17 & 0.09 \\
$\mathrm{Ag}$ & 1.5 & 0.24 & 1.05 & 0.59 \\
$\mathrm{Cu}$ & 52.29 & 7.31 & 5.74 & 19.56 \\
\hline
\end{tabular}

As shown in Table 5, when comparing Route 1-A and Route 1-B, although Route 1-A and Route 1-B are collecting WMPs under the same pattern, it is clear to see that Route 1-A have higher resource efficiency, especially when evaluation is done based on the area base. This could be because Route 1-A is collecting WMPs from Sendai city, which has a higher population density than other parts of the Miyagi prefecture.

On the other hand, Route 2 has the highest resource efficiency when evaluating from the population base. This is because despite the WMP collection stations being mainly built in the suburbs, the users are encouraged to use such a service since they can get 1 point from throwing $10 \mathrm{~g}$ of WMPs. It is also easy for users to use the service since the station opens $12 \mathrm{~h}$ per day and does not need extra paper work compared to other collection routes (such as telecom carriers). Furthermore, since the collection station was built by authorized recyclers, the users have little concern about their information stored in their WMPs. Therefore, although only a small part of the area installed collection stations, such a route can be expected as a method to improve the collection rate of WMPs and other small home appliances.

\section{Conclusions}

This study investigated the WMP collection routes in Japan and clarified the characteristics of each WMP collection route. The result shows that the local government, authorized WMP recyclers, and telecom carriers are the main agents in collecting WMPs in Japan.

As for the status of each WMP collection route, although it was found that local governments can collect WMPs stably, it is hard for local government to collect WMPs in low or regular-population density areas. The collection of WMPs was also shown to bring a heavy economic burden on local governments. Therefore, local governments lack motivation to improve the collection of WMP. In contrast, the WMP collection route established by the authorized recyclers was seen to be more efficient even in low-population 
areas. The resource efficiency of such a collection route for copper was especially high since the proportion of feature phones in the total collected WMP was high. Furthermore, telecom carriers were also focused on collecting used smartphones (especially iPhones). Although telecom carriers could collect the most WMPs, most of the collected mobile phones by telecom carriers are sold as secondhand phones instead of being recycled. Furthermore, since the need for secondhand mobile phones in Japan is small, and the secondhand mobile phone market is unmatured [29], these secondhand mobile phones will be exported abroad. This fact is inconsistent with the Japanese government's purpose to develop their domestic "urban mines".

Based on the above research result, to prompt the collection rate of WMPs in large cities with high population densities, using the collection route established by the local government as well as installing an authorized recycler's collection can be more effective, and the collection rate could be further improved by installing more collection boxes and stations. In cities with low population densities, the collection stations built by authorized recyclers are considered to be effective. This kind of collection route can nudge recycling behavior by offering points, which also helps customers improve recycling habits [30]. Furthermore, although the telecom carriers are also encouraged to participate in improving the WMP collection rate as a part of their CSR activities (Corporate Social Responsibility), they should figure out a way to monitor the flow route of secondhand phones that are exported and prompt the proper recycling of exported phones.

Author Contributions: Conceptualization, X.L. and J.Y.; methodology, X.L. and J.Y.; formal analysis, X.L., J.Y. and K.O.; investigation, X.L. and J.Y.; resources, X.L. and J.Y.; data curation, X.L., J.Y.; writing-original draft preparation, X.L. and J.Y.; writing—review and editing, X.L., J.Y. and K.O.; visualization, X.L., J.Y. and K.O.; supervision, X.L., J.Y. and K.O.; project administration, X.L., J.Y. and K.O.; funding acquisition, J.Y. All authors have read and agreed to the published version of the manuscript.

Funding: This research is supported by SEINAN Group.

Institutional Review Board Statement: Not applicable.

Informed Consent Statement: Not applicable.

Data Availability Statement: Not applicable.

Acknowledgments: This research is supported by SEINAN Group, we are grateful for all the data and samplings SEINAN Group kindly provided.

Conflicts of Interest: The authors declare no conflict of interest.

\section{Appendix A Interview Questions}

\section{Interview Questions for Local Government}

1. Questions about WEEEs collection

A. Could you tell me the specific collection WEEE collection method you use?

B. How many WEEEs have been collected these years through different collection routes?

C. The weight of collected WEEEs from this city is lower than that in other cities (in Tohoku area), what could be the reason?

D. What kind of problem you have when collecting WEEEs?

E. How many mobile phones can you get from the collected WEEEs?

F. Are used mobile phones recycled in the same way as other WEEEs?

G. Is there any possibility that used mobile phones could be exported through secondhand shop or other collection ways?

\section{Questions about policy and management}

A. How many authorized recyclers are you cooperating with currently? Could you tell me their name? 
B. Could you tell me the process of recycling WEEEs and your responsibilities?

C. What do you think about non-certified recycler in WEEE collection industry?

D. China is going to ban solid waste importation completely, does it bring new challenge for you in municipal waste management?

\section{Question about cost and benefit}

A. Is WEEEs recycling industry profitable?

B. How many costs does it take to collect WEEEs, and how many benefits could you get from selling WEEEs to the authorized recyclers?

C. Could you tell me the investment proportion of government's subsidy in the small household appliance recycling business?

\section{Interview Questions for Authorized Recyclers}

\section{Questions about WEEEs collection}

A. Could you tell me the specific WEEE collection method you use?

B. How many WEEEs have been collected these years through different collection routes? Could you tell me the proportion of mobile phones in collected WEEEs under different collection routes?

C. How many times will you collect WEEEs from the local government per month? What is the capacity of the truck for transportation?

\section{Questions about WEEEs Recycling}
A. Could you tell me your responsibilities in "Small Home Appliance Recycling Law" and WEEE recycling process?
B. Could you tell me the ratio of each type of mobile phones collected by each WMP collection route?
C. After dismantling the mobile phone, how do you deal with the body, battery, SIM card and charger?

\section{Other questions}
A. Will all the collected wastes be recycled in Japan?
B. China is going to ban solid waste importation completely, does it have any impact on your business?

\section{Interview Questions for Telecom Carriers}

\section{Question about WMPs Collection}
A. What kind of methods do you use to collect used mobile phones from your costumers?
B. How many WMPs have been collected in these years?
C. The amount of collected WMPs is decreasing, what could be the reason?
D. Could you tell me the ratio of each type of mobile phones you have collected? Is there any change in the ratio due to the widespread of smartphones?

2. Question about WMPs Recycling
A. How do you deal with the collected WMPs? What standard you use to deter- mine the way to deal with collected WMPs (reuse or recycle)?
B. Could you tell me the recycler's name you are cooperating with?
C. Will all the collected wastes be recycled in Japan? If not (for instance, some of them can be reused), which countries are importing the WMPs.
D. Could you tell me the number/ratio of exported mobile phones each year?

3. Other

A. China is going to ban solid waste importation completely, does it have any impact on your business? 


\section{References}

1. Ministry of Internal Affairs and Communications of Japan. Telecommunications Service. Available online: https://www.soumu. go.jp/johotsusintokei/whitepaper/ja/h23/pdf/n4030000.pdf (accessed on 10 December 2020).

2. Ministry of Internal Affairs and Communications. The Internet Penetration Rate. Available online: https://www.soumu.go.jp/ johotsusintokei/whitepaper/ja/h28/pdf/n5200000.pdf (accessed on 10 December 2020).

3. National Minerals Information Center. Mineral Commodity Summaries; National Minerals Information Center: Washington, DC, USA, 2017.

4. Ministry of the Environment Government of Japan. RECYCLE for 2020. Available online: https://www.env.go.jp/guide/info/ ecojin/issues/17-11/17-11d/tokusyu/2.html\#main_content (accessed on 10 December 2020).

5. Sustainability Design Institute Japan's Urban Mine Reserves. Available online: http://susdi.org/wp/data/post-79/ (accessed on 15 January 2021).

6. Sustainability Design Institute Quantitative Relationship between Japan's Urban Mine Reserves and Global Reserves. Available online: http:/ / susdi.org/wp/data/post-90/ (accessed on 20 January 2021).

7. Murakami, S.; Ohsugi, H.; Murakami-Suzuki, R.; Mukaida, A.; Tsujimura, H. Average Lifespan of Mobile Phones and in-Use and Hibernating Stocks in Japan. J. Life Cycle Assess. Jpn. 2009, 5, 138-144. [CrossRef]

8. Morise, T. “Urban Mine” Development-Current Status and Challenges. J. Jpn. Inst. Electron. Packag. 2008, 11, 413-417. [CrossRef]

9. Tsydenova, O.; Bengtsson, M. Chemical hazards associated with treatment of waste electrical and electronic equipment. Waste Manag. 2011, 31, 45-58. [CrossRef] [PubMed]

10. Nanjo, M. Bulletin of the Research Institute of Mineral Dressing and Metallurgy; Tohoku University: Sendai, Japan, 2008; pp. 239-251.

11. Mishima, K.; Nishimura, H. Requirement analysis to promote small-sized E-waste collection from consumers. Waste Manag. Res. 2016, 34, 122-128. [CrossRef] [PubMed]

12. Statista Research Department Number of Mobile and PHS Terminals Collected for Recycling Purposes in Japan from 2013 to 2018. Available online: https:/ / www.statista.com/statistics/754352/japan-number-mobile-phs-terminals-recycling/ (accessed on 17 January 2021).

13. Sugiyama, K.; Honma, O.; Mishima, N. Quantitative Analysis of Material Flow of Used Mobile Phones in Japan. In Proceedings of the Procedia CIRP; Elsevier B.V.: Amsterdam, The Netherlands, 2016; Volume 40, pp. 79-84.

14. Kodaira-shi Government Office Recycling of Small Household Appliances. Available online: http://www.city.kodaira.tokyo.jp.e. fj.hp.transer.com/kurashi/039/039329.html (accessed on 18 January 2021).

15. Atsushi TERAZONO Recycling Small Home Appliances and Metals in Japan. Available online: https://www-cycle.nies.go.jp/ eng/column/page/202005_01.html (accessed on 18 January 2021).

16. Mobile Recycle Network Collection Data. Available online: https://www.mobile-recycle.net/result/ (accessed on 31 December 2020).

17. Mishima, K.; Rosano, M.; Mishima, N.; Nishimura, H. End-of-Life Strategies for Used Mobile Phones Using Material Flow Modeling. Recycling 2016, 1, 122-135. [CrossRef]

18. Ministry of the Environment Government of Japan Test Result of Metal Content in Small Home Appliances. Available online: https:/ / www.env.go.jp/recycle/recycling/raremetals/conf_ruca/05/ref03.pdf (accessed on 20 January 2021).

19. Park, S.; Jung, M.; Kim, S.; Han, S.; Jung, I.; Park, J.; Park, J. Evaluation of Recycling Resources in Discarded Information and Communication Technology Devices (Smartphones, Laptop computers). J. Korean Inst. Resour. Recycl. 2018, $27,16-29$.

20. Saito, Y.; Yu, J. Developments in Small Size Home Appliance Recycling Policy in Japan: Current Status and Issues faced by Local Governments and Authorized Enterprises. MACRO Rev. 2015, 28, 1-12. [CrossRef]

21. Morishita, S. Outcome of Model Project for the Recycling of Rare Metals. Jpn. Soc. Waste Manag. Experts 2011, 22, 3-10.

22. Miyagi Prefectural Government Area and Population in Miyagi Prefecture. Available online: https://www.pref.miyagi.jp/ uploaded/attachment/664708.pdf (accessed on 31 December 2020).

23. Aomori Prefectural Government Area and Population in Aomori Prefecture. Available online: https://opendata.pref.aomori.lg. jp/dataset/dataland-409.html (accessed on 31 December 2020).

24. Hirosaki City Office Population Data of Hirosaki City. Available online: http:/ /www.city.hirosaki.aomori.jp/gaiyou/opendata/ population-past1.html (accessed on 31 December 2020).

25. Hokkaido Environment and Living Department Environment Bureau Recycling of Small Household Appliances. Available online: http: / / translate.google.co.jp/translate?sl=ja\&tl=en\&js=n\&prev=_t\&hl=en\&ie=UTF-8\&u=http $\% 3 \mathrm{~A} \% 2 \mathrm{~F} \% 2 \mathrm{Fwww}$.pref. hokkaido.lg.jp\%2Fks\%2Fjss\%2Fgrp\%2Fkogatakaden\%2Findex.htm (accessed on 31 December 2020).

26. Sugimura, Y.; Murakami, S. Problems in Japan's Governance System Related to End-of-life Electrical and Electronic Equipment Trade. Resour. Conserv. Recycl. 2016, 112, 93-106. [CrossRef]

27. NTT DOCOMO Annual Operating Data about DOCOMO. Available online: https://www.nttdocomo.co.jp/english/corporate/ ir/finance/operator/ (accessed on 18 January 2021).

28. Department of Business Statistics Economic and Social Research Institute Cabinet Office, Government of Japan. Consumer Confidence Survey. Available online: https:/ / www.esri.cao.go.jp/jp/stat/shouhi/honbun.pdf (accessed on 31 December 2020).

29. Yamauchi, K.; Chen, W.; Wei, D. A Study on Japanese Mobile Phone Market and Its Applications. In Proceedings of the Fourth International Conference on Computer and Information Technology (CIT 2004), Wuhan, China, 16 September 2004; pp. 875-878.

30. Miliute-Plepiene, J.; Hage, O.; Plepys, A.; Reipas, A. What Motivates Households Recycling Behaviour in Recycling Schemes of Different Maturity? Lessons from Lithuania and Sweden. Resour. Conserv. Recycl. 2016, 113, 40-52. [CrossRef] 